\title{
Low-Frequency Variability and Possible Changes in the North Pacific Simulated by CMIP5 Models
}

\author{
Jiangman WANG \\ Physical Oceanography Laboratory/CIMST, \\ Ocean University of China and Qingdao National Laboratory for Marine Science and Technology, China \\ Key Laboratory of Ocean-Atmosphere Interaction and Climate in Universities of Shandong, \\ Ocean University of China, China \\ Qingdao Marine Disaster Reduction Center, Qingdao Municipal Ocean and Fisheries Administration, China \\ and

\section{Chun LI} \\ Physical Oceanography Laboratory/CIMST, \\ Ocean University of China and Qingdao National Laboratory for Marine Science and Technology, China \\ Key Laboratory of Ocean-Atmosphere Interaction and Climate in Universities of Shandong, \\ Ocean University of China, China
}

(Manuscript received 25 July 2016, in final form 27 February 2017))

\begin{abstract}
The Pacific Decadal Oscillation (PDO) and North Pacific Gyre Oscillation (NPGO) are the two dominant lowfrequency modes in the North Pacific. This study focused on the simulation capability of the two leading lowfrequency modes in current-coupled models, based on 24 coupled model outputs from the Coupled Model Intercomparison Project Phase 5 (CMIP5). Results showed that most of these models captured the two low-frequency modes, but the air-sea coupling relationship (covariability of the ocean low-frequency modes with the atmospheric forcing modes) captured by CMIP5 models had drastic differences. Four models (CCSM4, CESM-WACCM, MIROC5, and NorESM1-M) not only captured the spatial and temporal characteristics of the PDO and NPGO modes but also simulated their air-sea coupling relationships. Therefore, we selected these four models to examine changes in the PDO and NPGO modes under different global warming scenarios using RCP4.5 and RCP8.5 forcing (RCP: Representative Concentration Pathway). In future RCP scenarios, the spatial patterns of PDO and NPGO showed no obvious changes. However, the dominant periods of the PDO and NPGO modes were shorter, which is consistent with faster oceanic Rossby waves induced by enhanced upper oceanic stratification in the warming scenarios.
\end{abstract}

Keywords Pacific Decadal Oscillation; North Pacific Gyre Oscillation; air-sea coupling relationship; global warming

Corresponding author and present affiliation: Jiangman Wang, Qingdao Municipal Ocean and Fisheries Administration, Ocean Building, No.18, Kaohsiung Road, Qingdao, Shandong Province, China

E-mail: m daisy@foxmail.com

J-stage Advance Published Date: 22 March 2017

(C)2017, Meteorological Society of Japan 


\section{Introduction}

In the North Pacific, low-frequency variability is characterized by two dominant modes: the Pacific Decadal Oscillation (PDO; Mantua et al. 1997) and North Pacific Gyre Oscillation (NPGO; Di Lorenzo et al. 2008). PDO, as the leading mode of sea surface temperature anomalies (SSTA) in the North Pacific, is characterized by a horseshoe-like pattern with the opposite sign of sea surface temperature anomalies (SSTA) in the central North Pacific as the west coast of North America. The NPGO, represented by a north-south dipole mode in the North Pacific, is defined as the second dominant mode of sea surface height anomalies variability in the Northeast Pacific, which is closely related to the second mode of North Pacific SSTA (Di Lorenzo et al. 2008).

The physical mechanisms of PDO and NPGO have been investigated. Several views have been proposed, including the North Pacific coupled ocean-atmosphere interaction (Chhak et al. 2009; Di Lorenzo et al. 2010), the combined effect of ocean and high-frequency atmosphere variability (Newman et al. 2003), and the tropical and extratropical teleconnections (Vimont et al. 2003; Wang et al. 2012). Moreover, the corresponding atmospheric forcing patterns related to PDO and NPGO are the variability of the Aleutian Low (AL; Graham 1994) and the variability of the North Pacific Oscillation (NPO; Walker and Bliss 1932; Rogers 1981), respectively. To systematically organize the mechanisms above, Di Lorenzo et al. (2009) established a conceptual schematic of the Pacific climate variability, including the connections between low-frequency ocean variations (PDO/NPGO), the related atmospheric forcing patterns (AL/NPO), and the El Niño-Southern Oscillation (ENSO) cycle. However, dynamic mechanisms of ocean variability in the North Pacific seem to be different between the observations and the climate models. Studies focused on the mechanisms of PDO using climate models indicated that PDO is driven mainly by local atmospheric forcing (AL variability), while forcing signals outside of the North Pacific have no obvious effects. Meanwhile, ocean dynamic processes have not been well simulated (Park et al. 2013).

In recent years, global warming has led to irreversible climate change and affected large-scale modes of climate variability. Studies concerning climate variability in the context of global warming are ongoing. Saenko (2006) indicated that global warming can enhance ocean stratification and accelerate Rossby waves, which may weaken PDO and move it to a higher frequency (Fang et al. 2014; Zhang and Delworth 2016). Some studies indicate that greenhouse gas forcing will lead to a weak and insignificant shift in PDO early in the 21 st century (Lapp et al. 2011).

Thus far, studies concerning PDO and NPGO simulated by climate models are in progress. Using climate models in the Intergovernmental Panel on Climate Change (IPCC) Fourth Assessment Report (AR4), Furtado et al. (2011) found that there is considerable diversity of PDO and NPGO in terms of spatial patterns and temporal characteristics among the models, while their capability to capture the corresponding atmospheric forcing patterns is also questionable. Yim et al. (2015) obtained better air-sea coupling relationships for PDO using CMIP5 models compared to CMIP3 models. However, less attention has been paid to the NPGO mode and its reproducibility by climate models and to possible changes of both PDO and NPGO in the context of global warming.

This study evaluates PDO and NPGO as well as the corresponding air-sea coupling relationships simulated by 24 CMIP 5 models. In addition, to diminish the influence of the intermodal spread, four representative models with better performance for the local air-sea coupling relationship are selected and evaluated. Possible changes in spatial and temporal characteristics of PDO and NPGO in future emission scenarios are also discussed.

This paper is arranged as follows: the data methods used in this study are described in Section 2. PDO and NPGO simulated by CMIP5 models as well as the airsea coupling relationship are examined in Section 3. In Section 4, four representative models are selected with better air-sea coupling relationships, and their multimodel ensemble results are investigated. The conclusion and discussion are provided in Section 5.

\section{Data and methods}

\subsection{Observations}

The two leading modes in the North Pacific are examined using the analysis of SST and SLP. Both SST and SLP data are taken from the National Oceanic and Atmospheric Administration Twentieth Century Reanalysis dataset (Twentieth Century Reanalysis, 20CR, Compo et al. 2011), which contains monthly mean values from 1901-2005, horizontal spatial resolution of $2^{\circ} \times 2^{\circ}$.

\subsection{Model output}

We use 24 coupled climate models from the World Climate Research Programme's CMIP5 multimodel dataset (Table 1). One can find detailed information 
on the CMIP5 models and experiments at http://cmippcmdUlnLgov/cmip5/index.html.

Similar to the CMIP3 project, we use the historical run to represent the 20th century climate. Simulation outcomes of new scenarios referred to as "Representative Concentration Pathways (RCPs)" (IPCC 2013) are assessed to explore changes in the future climate in the context of global warming. RCP4.5 and RCP8.5 scenarios (i.e., radiative forcing at 2100 reach about 4.5 or $8.5 \mathrm{~W} \mathrm{~m}^{-2}$ ) are used to represent the future climate with different emissions of greenhouse gases.

The SST and SLP fields of the models and the observations are interpolated into the same grids (i.e., $1^{\circ} \times 1^{\circ}$ for SST and $2.5^{\circ} \times 2.5^{\circ}$ for SLP) for ease of comparison.
Only the boreal winter season (December-February) is chosen as the North Pacific ocean-atmosphere coupling is dominant in that season. This study uses the historical runs from 1901 to 2005 consistent with the observations and the future runs from 2006 to 2100 .

\subsection{Statistical techniques}

Primarily, we use empirical orthogonal function (EOF) to isolate patterns of climate variability in the North Pacific. For EOF analysis, each field is weighted by the square root of the cosine of latitude. The anomalous fields are calculated by removing the climatological monthly mean, and the EOF results are normalized by their standard deviation. Only two dominant modes are retained as both of them pass the

Table 1. Information on the 24 IPCC AR5 coupled models used in this study

\begin{tabular}{|c|c|c|c|c|}
\hline \multirow{2}{*}{ Originating group } & \multirow{2}{*}{ Country } & \multirow{2}{*}{ Model name } & \multicolumn{2}{|c|}{ Resolution (lon × lat) } \\
\hline & & & Atmosphere & Ocean \\
\hline $\begin{array}{l}\text { Commonwealth Scientific and Industrial Research } \\
\text { Organization (CSIRO) and Bureau of Meteorology (BOM) }\end{array}$ & Australia & ACCESS1-0 & $192 \times 145$ & $360 \times 300$ \\
\hline $\begin{array}{l}\text { Beijing Climate Center, China Meteorological } \\
\text { Administration }\end{array}$ & China & $\begin{array}{l}\text { bcc-csm1-1 } \\
\text { bcc-csm1-1-m }\end{array}$ & $\begin{array}{l}128 \times 64 \\
320 \times 160\end{array}$ & $\begin{array}{l}360 \times 232 \\
360 \times 232\end{array}$ \\
\hline Canadian Center for Climate Modeling and Analysis & Canada & CanESM2 & $128 \times 64$ & $256 \times 192$ \\
\hline National Center for Atmospheric Research & USA & CCSM4 & $288 \times 192$ & $384 \times 320$ \\
\hline Community Earth System Model Contributors & USA & $\begin{array}{l}\text { CESM1-BGC } \\
\text { CESM1-CAM5 } \\
\text { CESM1-FASTCHEM } \\
\text { CESM1-WACCM }\end{array}$ & $\begin{array}{l}288 \times 192 \\
288 \times 192 \\
288 \times 192 \\
144 \times 96\end{array}$ & $\begin{array}{l}384 \times 320 \\
384 \times 320 \\
384 \times 320 \\
384 \times 320\end{array}$ \\
\hline Centro Euro-Mediterraneo per I Cambiamenti Climatici & Italy & CMCC-CMS & $192 \times 96$ & $182 \times 149$ \\
\hline Centre National de Researches Meteorologiques & France & CNRM-CM5 & $256 \times 128$ & $362 \times 292$ \\
\hline $\begin{array}{l}\text { Commonwealth Scientific and Industrial Research } \\
\text { Organization in collaboration with Queensland Climate } \\
\text { Change Centre of Excellence }\end{array}$ & Australia & CSIRO-Mk3-6-0 & $192 \times 96$ & $192 \times 189$ \\
\hline The First Institute of Oceanography & China & FIO-ESM & $128 \times 64$ & $384 \times 320$ \\
\hline $\begin{array}{l}\text { LASG, Institute of Atmospheric Physics, Chinese } \\
\text { Academy of Sciences }\end{array}$ & China & FGOALs-g2 & $128 \times 60$ & $360 \times 196$ \\
\hline NOAA Geophysical Fluid Dynamics Laboratory & USA & GFDL-CM3 & $144 \times 90$ & $144 \times 90$ \\
\hline NASA Goddard Institute for Space Studies & USA & GISS-E2-H & $144 \times 90$ & $144 \times 90$ \\
\hline National Institute of Meteorological Research & Korea & HadGEM2-AO & $192 \times 145$ & $360 \times 216$ \\
\hline Institute for Numerical Mathematics & Russia & Inmcm4 & $180 \times 120$ & $360 \times 340$ \\
\hline Institute Pierre-Simon Laplace & France & $\begin{array}{l}\text { IPSL-CM5A-MR } \\
\text { IPSL-CM5B-LR }\end{array}$ & $\begin{array}{l}96 \times 96 \\
96 \times 96\end{array}$ & $\begin{array}{l}182 \times 149 \\
182 \times 149\end{array}$ \\
\hline $\begin{array}{l}\text { Atmosphere and Ocean Research Institute (the University } \\
\text { of Tokyo), National Institute for Environmental Studies, } \\
\text { and Japan Agency for Marine-Earth Science and Technology }\end{array}$ & Japan & $\begin{array}{c}\text { MIROC5 } \\
\text { MIROC-ESM-CHEM }\end{array}$ & $\begin{array}{l}256 \times 224 \\
128 \times 64\end{array}$ & $\begin{array}{l}256 \times 224 \\
256 \times 192\end{array}$ \\
\hline Max Planck Institute for Meteorology & Germany & MPI-ESM-LR & $192 \times 96$ & $256 \times 220$ \\
\hline Norwegian Climate Centre & Norwegian & NorESM1-M & $144 \times 96$ & $320 \times 384$ \\
\hline
\end{tabular}


significant test of North et al. (1982).

To quantify the atmospheric forcing effect on the oceanic modes, we regress the PCs of two dominant modes of SLPA onto the SSTA field of each model and then calculate the correlation between the regression patterns and original SSTA dominant patterns. Models with high correlation coefficients are selected for simulating the SSTA dominant modes and the air-sea coupling characteristics well. Then spectral analysis is used to explore the temporal characteristics of the dominant SSTA modes. Furthermore, the selected models are used to assess the spatial and temporal performance in two future emission scenarios.

Multimodel ensemble statistics are used in this paper to represent the integrated models' simulation capabilities. First, the EOF is computed for each model, and then the leading modes of each model are averaged together. Similarly, for power spectra, the individual normalized power spectra of the models are averaged together to get the ensemble-mean power spectrum.

\section{Two SSTA dominant modes of the North Pacific in CMIP5 models}

\subsection{Spatial characteristics}

Spatial patterns of two dominant SSTA modes in the North Pacific in winter as found in 24 models and in observations are presented in Figs. 1 and 2. The variance contribution of each mode is given after the model name. The correlation coefficients of the two dominant modes between models and observations are marked on the right corner of each panel. It is shown that most of the models are able to simulate the PDO spatial pattern as the first mode whereas few models cannot. The spatial pattern of the second mode in most models exhibits a northeast-southwest-oriented triple that is identical to the NPGO pattern. The first mode is better simulated than the second mode based on a comparison of correlation coefficients (Figs. 1, 2). The simulation capabilities of the two dominant SSTA modes have been improved compared with those of CMIP3, which is consistent with previous findings (Furtado et al. 2011; Yim et al. 2015).

To quantitatively evaluate simulated performance

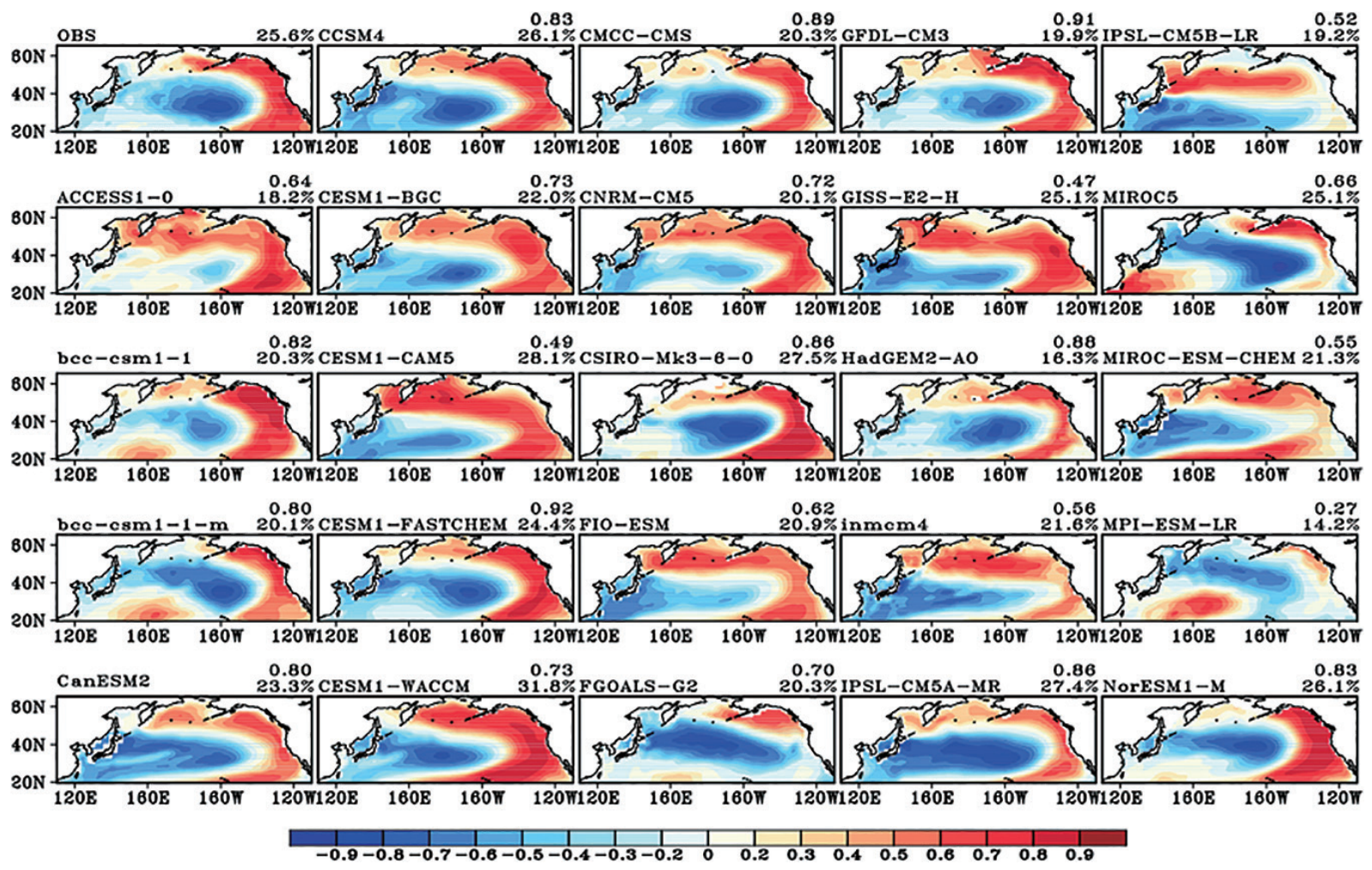

Fig. 1. The first EOF mode of the North Pacific winter mean SSTA in the 24 CGCMs and in the observations (shaded, unit: $\left.{ }^{\circ} \mathrm{C}\right)$. 
of the two dominant modes in each model, a Taylor diagram is shown in Fig. 3, following the method of Taylor (2001). A Taylor diagram compares models with observations based on the standard deviation ratio and the pattern correlation coefficient. The radial distance from the origin to the points represents the ratio of standard deviations (RSD), and the azimuthal positions represent the pattern correlation coefficient (PCC). The closer the distance to $(1,0)$, the better a spatial pattern is simulated. As Fig. 3 shows, most models simulate EOF1 well, the value of PCC varies from 0.6 to 0.95 , and the values of RSD are distrib-
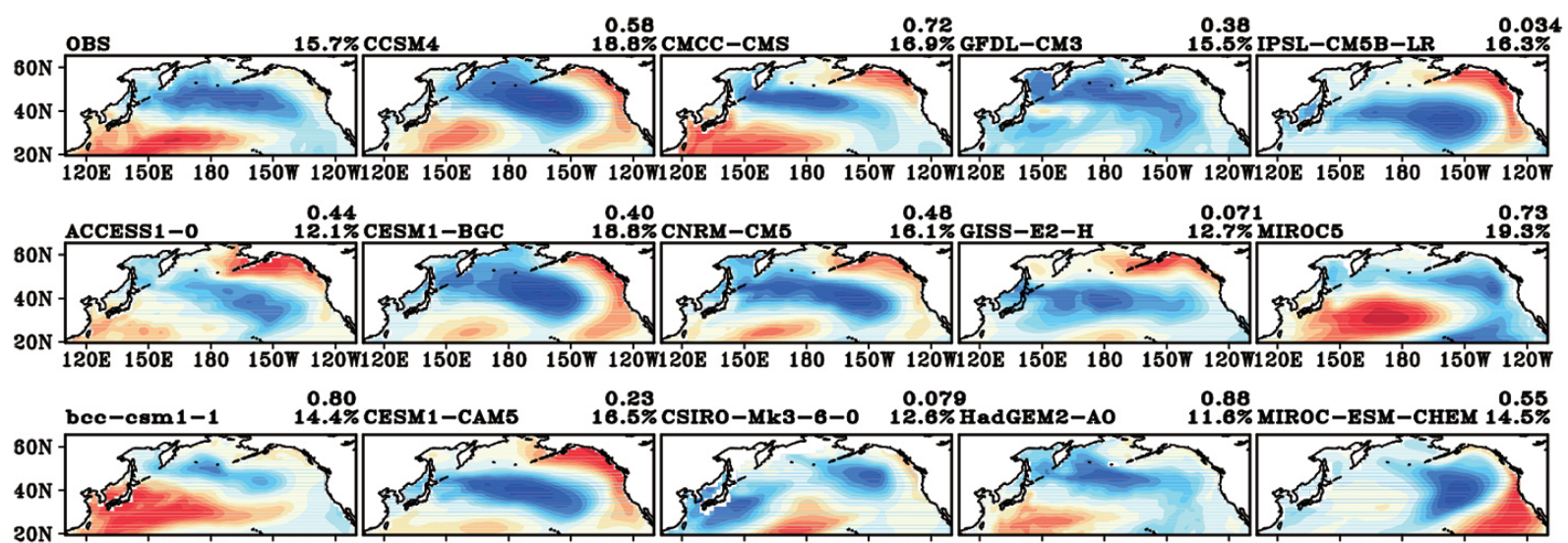

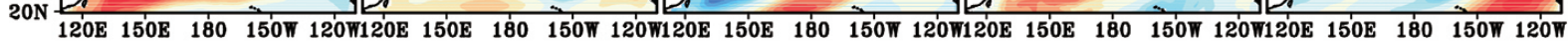
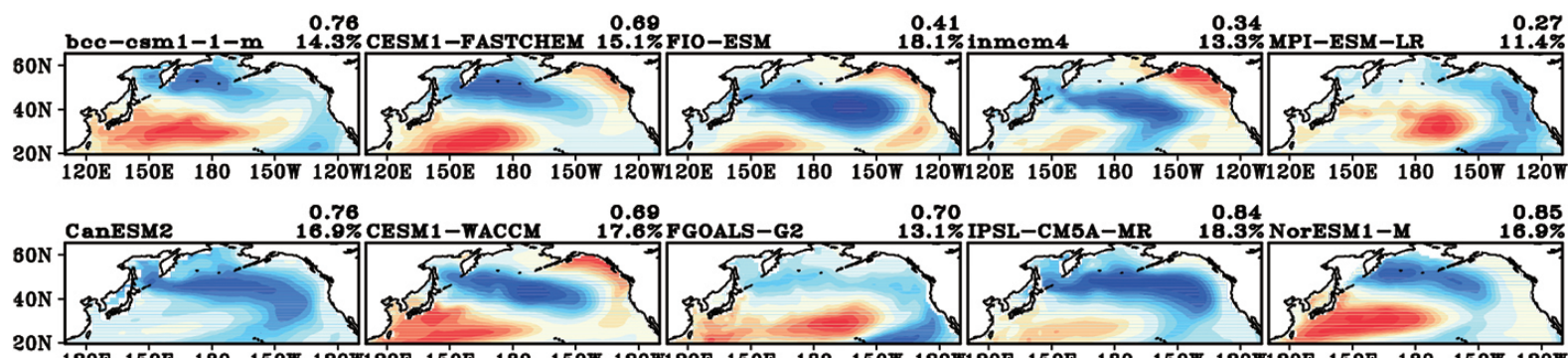

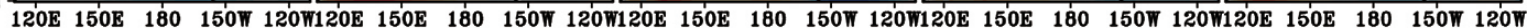

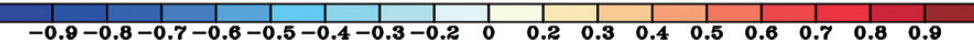

Fig. 2. Same as Fig. 1, but for the second EOF mode.
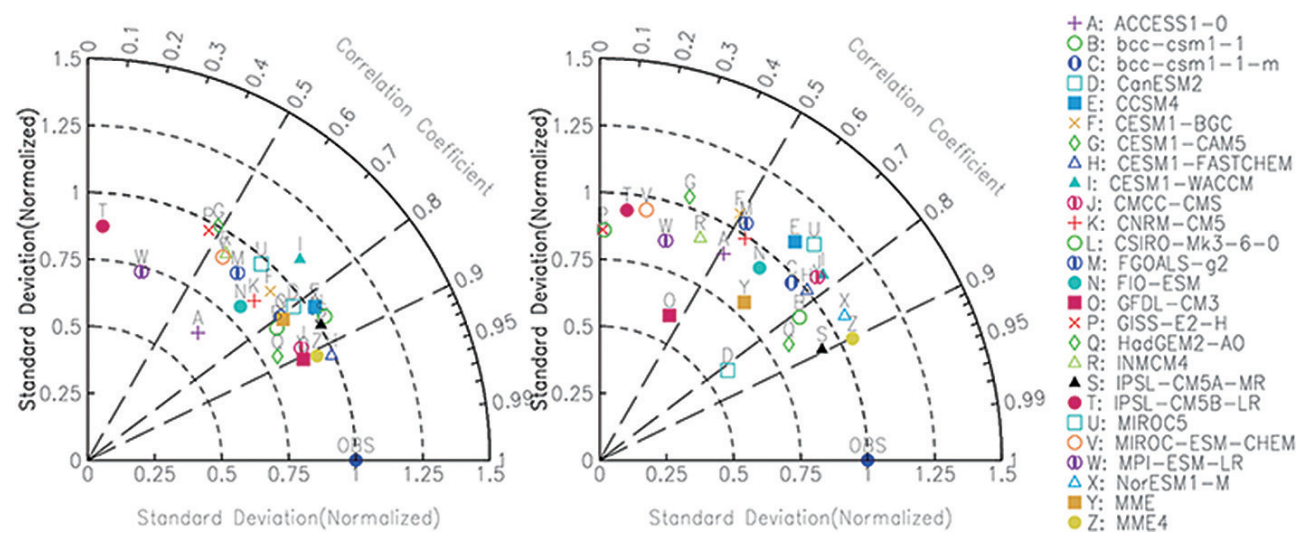

Fig. 3. Taylor diagram describing the relationship between the two SSTA dominant modes of each model and that of the observations (including MME and MME4 discussed below). The radial distances from the origin to the points represent the RSD; the azimuthal positions are determined by the PCC. 
uted between 0.7 and 1.1 with most of the models underestimating the amplitude of EOF1. However, for EOF2, both PCC and RSD show obvious intermodal spread. For example, PCC is only 0.013 in the GISSE2-H model but reaches 0.89 in the IPSL-CM5A-MR model. The values of RSD range from 0.5 to 1.25 . This denotes that the CMIP5 models' simulation capability of NPGO is still weaker than that of PDO.

\subsection{Air-sea coupling relationship}

As mentioned previously, PDO and NPGO are determined by both intrinsic variability in the ocean and external forcing by the local atmosphere (Chhak et al. 2009). Nevertheless, in climate models, low-frequency modes in the North Pacific are mainly forced by atmosphere variability and are little related to tropicextratropic teleconnection. In this section, we mainly evaluate the air-sea coupling relationship in the North Pacific in 24 CMIP5 models. Before analyzing the air-sea coupling relationship of the leading modes in the North Pacific, two dominant modes of atmospheric variability from each model are compared to observations. In most models, EOF1 of the SLPA exhibits the AL pattern (Fig. 4) and EOF2 shows the NPO pattern (Fig. 5); for EOF1, seven models' correlation coefficients of the observed AL pattern reached 0.85, and for EOF2, 10 models' correlation coefficients of the observed NPO pattern reached 0.85 . This shows some progress in the simulation of atmospheric variability by the CMIP5 models compared to that by the CMIP3 models, especially for the second mode (Furtado et al. 2011).

To study whether CMIP5 models are capable of simulating air-sea coupled relationships in the North Pacific, we regress the leading two PCs of the North Pacific SLPA onto the North Pacific SSTA (Figs. 6, 7) and the regressed patterns of each model are shown in Figs. 6 and 7. As shown in Fig. 6, the first regression pattern is identical with PDO in most models, whereas several models display the NPGO pattern. Additionally, some models show that the regression of PC-1 of the SLPA variability onto the North Pacific SSTA yields an NPGO-like signature despite their leading mode of the SSTA variability being PDO. This result indicates that in these models, the orders of oceanic modes are inconsistent with direct atmospheric forcing modes, implying that atmospheric forcing may not be the primary factor driving the oceanic variability in these models. Figure 7 presents a greater model spread of the second regression pattern; most models fail to regress the NPGO type, suggesting that the reproducibility of the NPGO-NPO covariability by
CMIP5 models remains questionable. Furthermore, the discrepancies actually affect confidence in climate variability simulations. Hence, to optimize simulation results and favor follow-up research, we select models that perform well in simulating air-sea coupling relationship of PDO and NPGO. To compare the simulation skills of air-sea coupling relationship among CMIP5 models, we use the Taylor diagram as well (Fig. 8). The dominant SSTA modes are compared with the atmospheric regressed SSTA modes of each model. The radial distance from the origin to a point represents the standard deviation ratio of the regressed pattern to the SSTA dominant pattern (RSD), and the azimuthal position represents the pattern correlation coefficient between them (PCC). Different from Fig. 3, in this Taylor diagram, the closer one's distance to $(1,1)$, the more similar the atmospheric regressed pattern to the SSTA dominant pattern, and the SST leading mode is closer to an atmospheric forcing mode.

For the first mode, the PCC exhibits an obvious intermodal diversity; the values of the PCC range from 0 to 0.95 (whose value is 0.87 in the observations). The presence of low values should be attributed to differences in spatial characteristics between the atmospheric regressed pattern and the original SSTA pattern in some models. The RSD values vary from 0.4 to 0.8 (whose value is 0.55 in the observations), which is slightly lower than the previous findings $(0.5-0.8$; Park et al. 2013). This may be a result of differing delineations of the scope of the atmospheric field between the present study $\left(20^{\circ} \mathrm{N}-65^{\circ} \mathrm{N}, 120^{\circ} \mathrm{E}-110^{\circ} \mathrm{W}\right)$ and the previous study $\left(30^{\circ} \mathrm{N}-65^{\circ} \mathrm{N}, 160^{\circ} \mathrm{E}-140^{\circ} \mathrm{W}\right)$. Eleven models (D, E, F, I, L, M, P, R, S, U, and X) show strong consistency between the atmospheric regressed pattern and SSTA dominant pattern. Then for the second mode, both RSD and PCC exhibit great model spread. The values of RSD are between 0.1 and 0.6 (whose value is 0.55 in the observations), whereas the values of PCC range from 0 to 0.9 (whose value is 0.76 in the observations). Six models (E, I, M, P, $\mathrm{U}$, and $\mathrm{X}$ ) show better performance in simulating the second mode. In addition, for models $\mathrm{M}$ and $\mathrm{P}$, the first simulated SSTA mode depicts an NPGO pattern and the second SSTA mode shows a PDO pattern, which is different from the observations. From the analysis above, four models (E: CCSM4, I: CESM-WACCM, U: MIROC5, and X: NorESM1-M) are selected with better performance in simulating the air-sea coupling relationship, both for PDO and NPGO. In the next section, a multimodel ensemble analysis of these four models (MME4) will be conducted. 

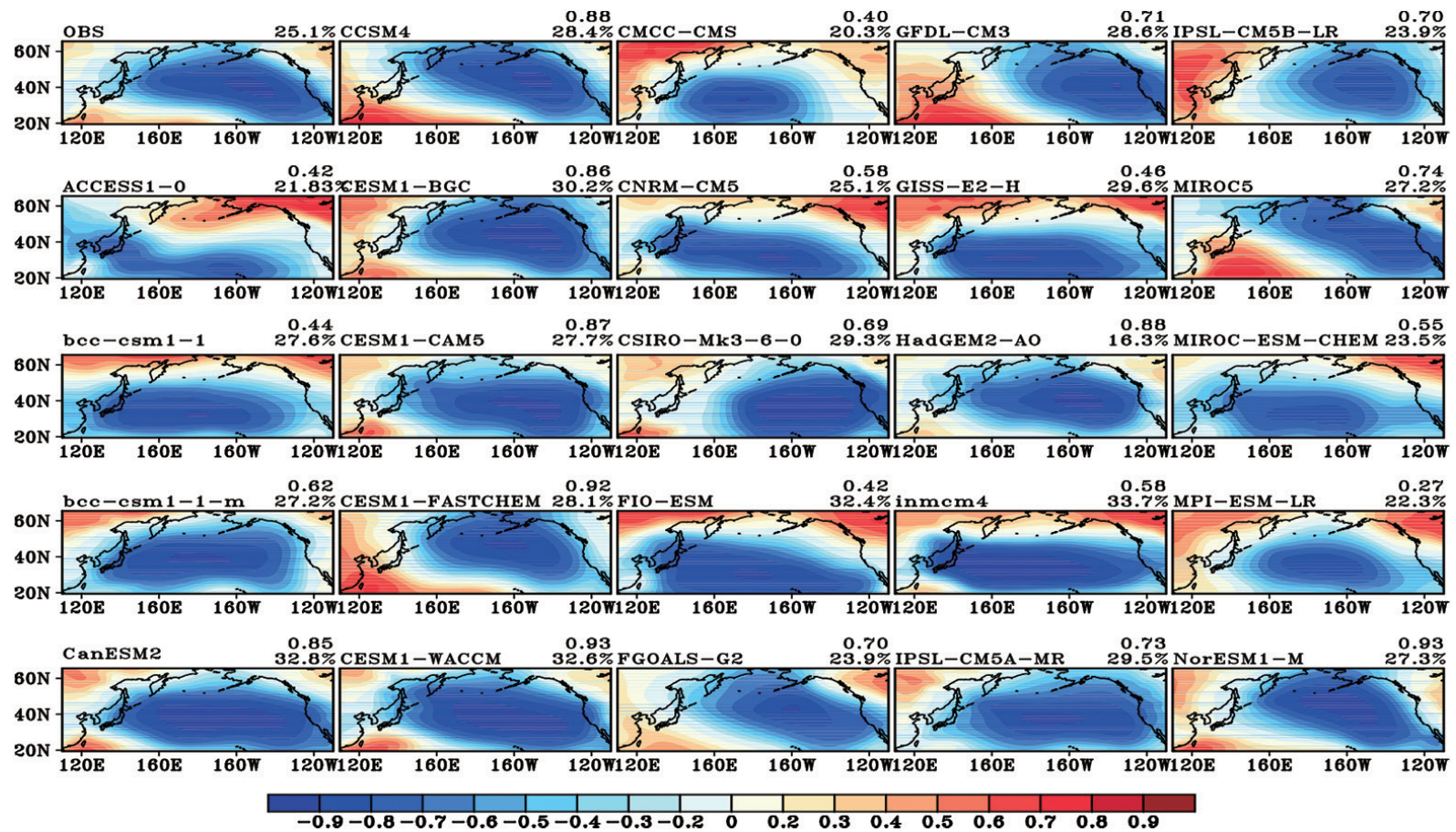

Fig. 4. The first EOF mode of the North Pacific winter mean SLPA in the 24 CGCMs and in the observations.
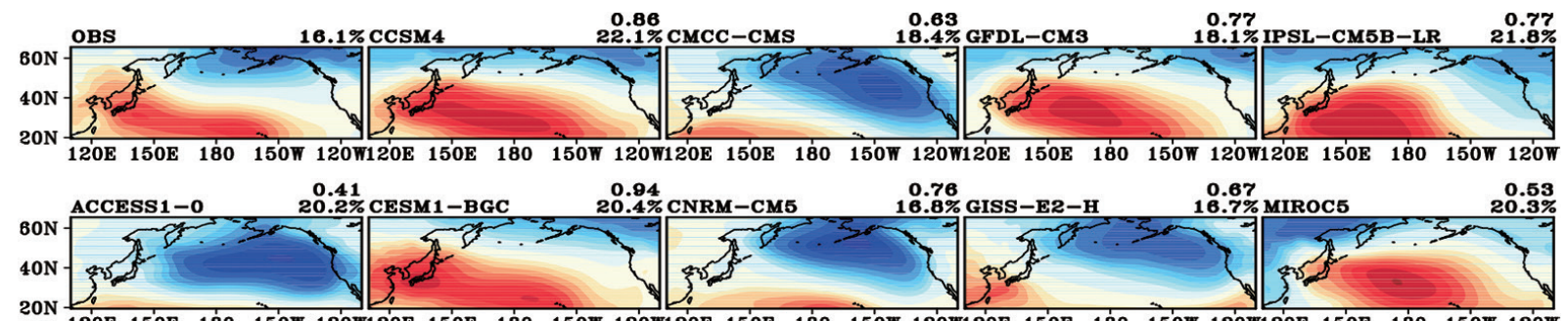

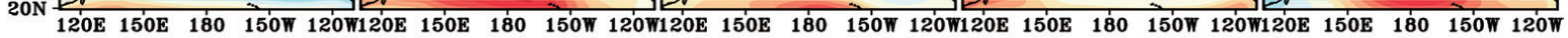
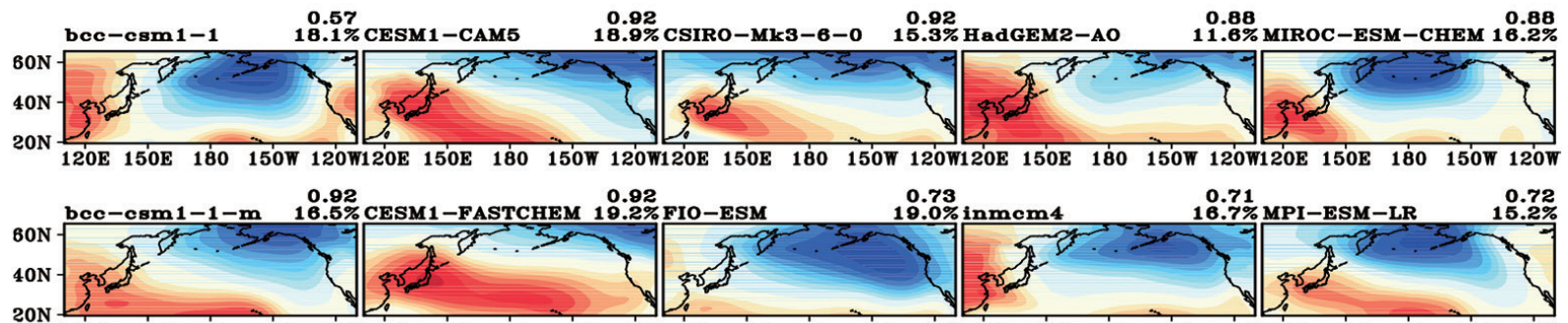

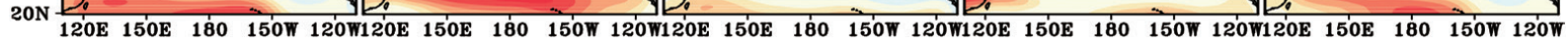
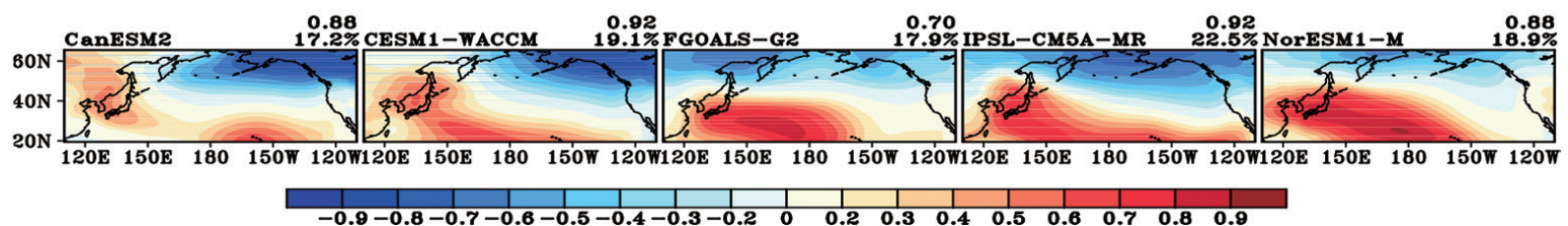

Fig. 5. Same as Fig. 4, but for the second SLPA EOF mode. 

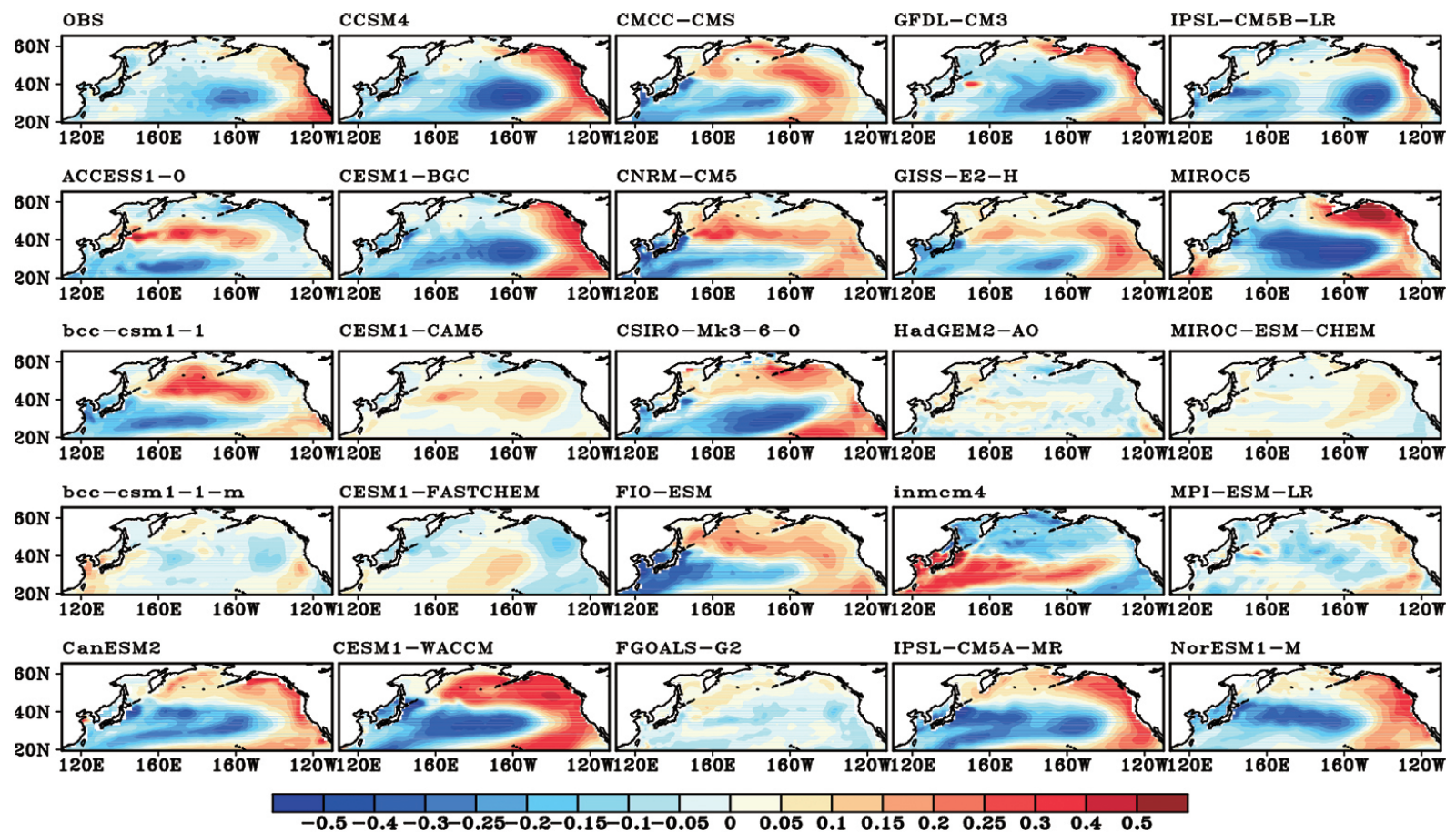

Fig. 6. Linear regressions of the North Pacific winter mean SSTA with respect to the time series of the first

SLPA EOF mode in the 24 CGCMs and that in the observations.
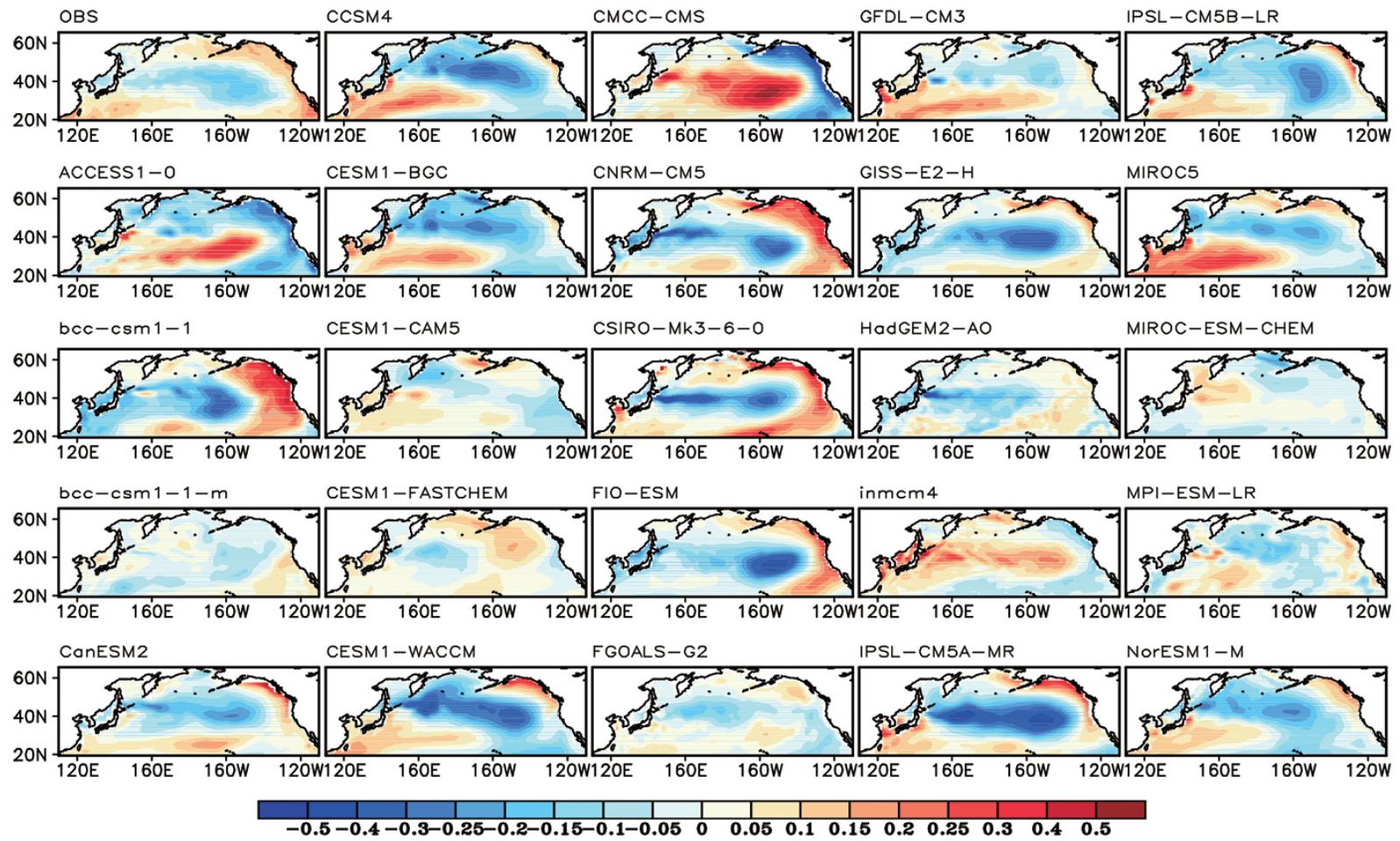

Fig. 7. Same as Fig. 6, but for the second SLPA EOF mode. 

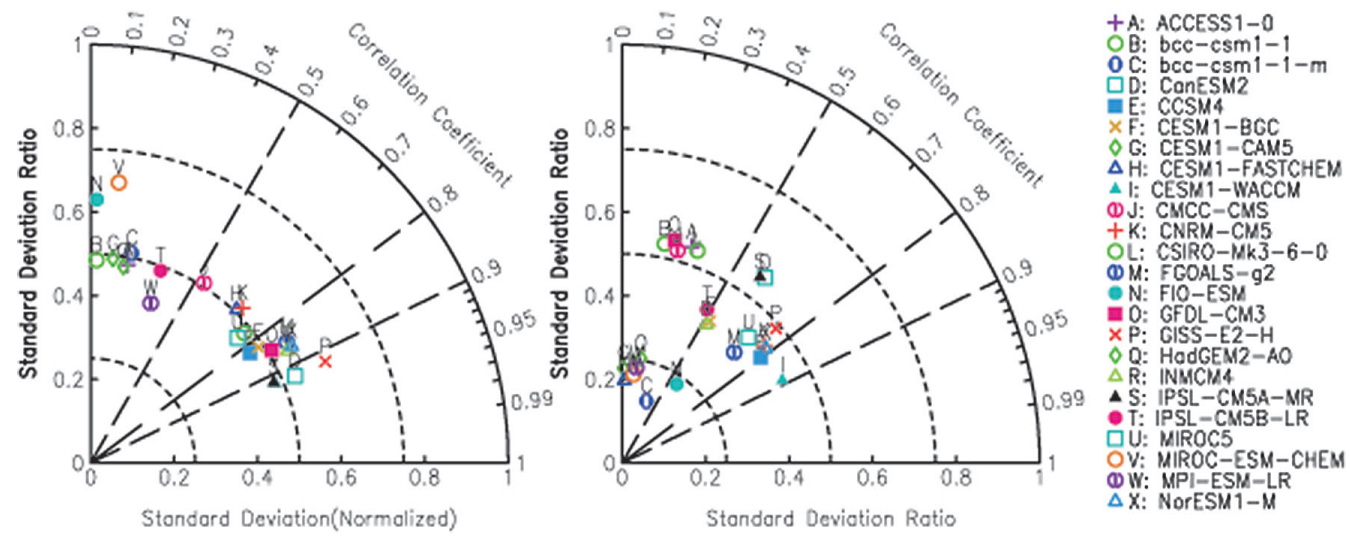

Fig. 8. Taylor diagram describing the relationship between the atmospheric regressed patterns and the SSTA dominant patterns of NPDV in each model (OBS result is given for comparison). The radial distance from the origin to the points represent the RSD of the regressed patterns to the SSTA dominant patterns, and the azimuthal positions represent the PCC between them.

\section{PDO and NPGO in MME4 in present and future climates}

\subsection{Spatial characteristics in the present climate}

The spatial characteristics of the two dominant modes of SSTA and SLPA of the four selected models' multimodel ensemble mean (MME4) are shown in Fig. 9. One can see that the spatial characteristics of the SSTA dominant modes (Figs. 9a, c) are significantly correlated with the observations, whereas the correlation between the unselected MME and the observations are relatively poor. It can be visually observed from the Taylor diagram in Fig. 3 that MME4 shows a stronger ability to simulate the spatial patterns of PDO and NPGO than the MME. In addition, the first SLPA mode (Fig. 9b) presents an AL pattern and the second mode exhibits an NPO pattern (Fig. 9d), which is highly consistent with the observations. The analysis above indicates that the MME4 better simulates the spatial patterns of oceanic and atmospheric dominant modes in the North Pacific compared to any single model or MME.

\subsection{Temporal characteristics in historical scenarios}

The capability of CMIP3 models to capture the temporal characteristics of PDO and NPGO is unsatisfactory. Considering that CMIP5 models have progressed compared to CMIP3 models, MME4 is used to evaluate the simulation of temporal characteristics of PDO and NPGO. Here we use the ensemble-mean time series of these four models based on the previous section without considering the slight difference between the ensemble temporal period and the single model (Fleming et al. 2016). As shown in Fig. 10, the peak of the PDO power spectrum is located at 15-25 years in the observation data. For MME4, the PDO's main period is around 8-15 years. The shorter period in MME4 may be attributed to the defective air-sea coupling process simulation in models, which relates to a discrepancy in designing the physical mechanism (Zhang and Delworth 2015). Because the data length is limited, longer periods cannot be captured. The power spectrum of NPGO in the observations has two peaks, around 20 and 8 years, which is consistent with a previous study (Yi et al. 2015); there is also a prominent decadal period around 15 years for the MME4 simulated NPGO. The analysis above shows that the MME4 makes some progress toward capturing the PDO and NPGO cycle, although the prominent periods of PDO and NPGO are hard to capture either in a single model or in MME. In summary, the MME4 displays good simulation performance of both spatial and temporal characteristics of PDO and NPGO, indicating that the models' simulation results are more accurate after the step of model selection.

\subsection{Spatial and temporal characteristics in future scenarios}

Earlier studies demonstrated that global warming would cause some changes in climate variability. Using a coupled model named FOAM, Fang et al. (2014) discovered that PDO may shift to a higher frequency under global warming conditions. However, few studies focus on changes in PDO and NPGO 
(a) EOF1_SST_MME4(22.7\%) 0.91
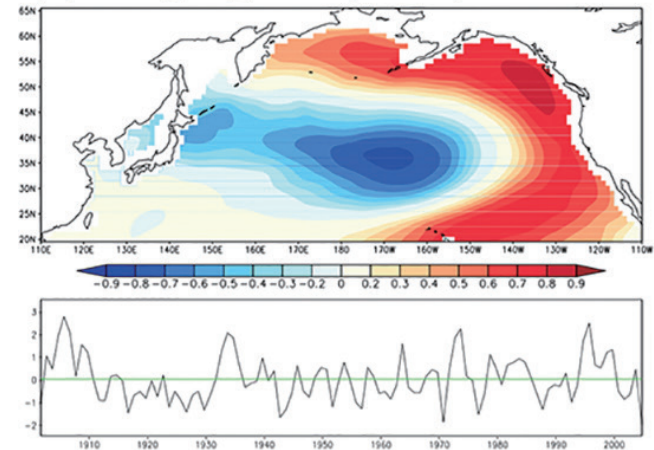

(c) EOF2_SST_MME4(16.9\%)
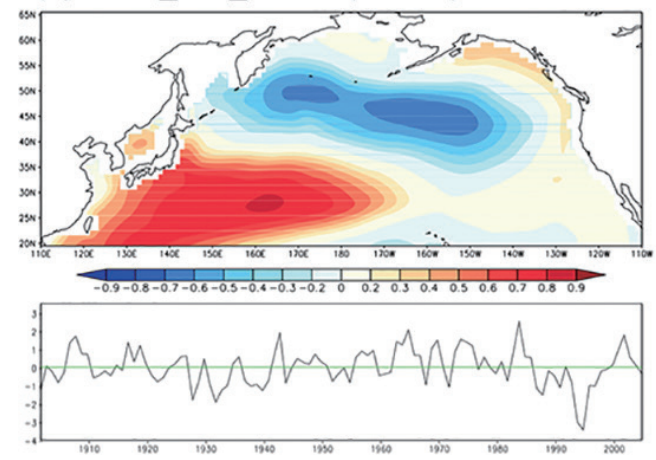

(b) EOF1_SLP_MME4(29.8\%) 0.96
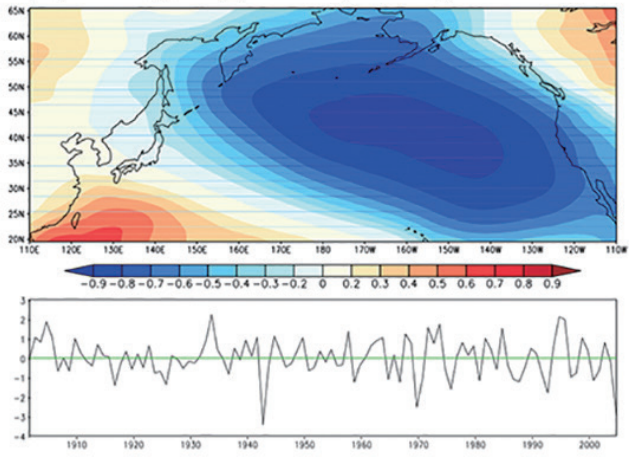

(d) EOF2_SLP_MME4(17.2\%) 0.88

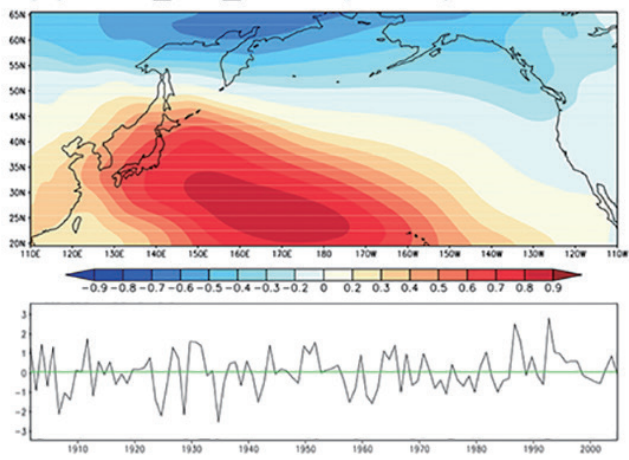

Fig. 9. Two dominant EOF modes of the North Pacific winter mean SSTA and SLPA in historical scenario in MME4.

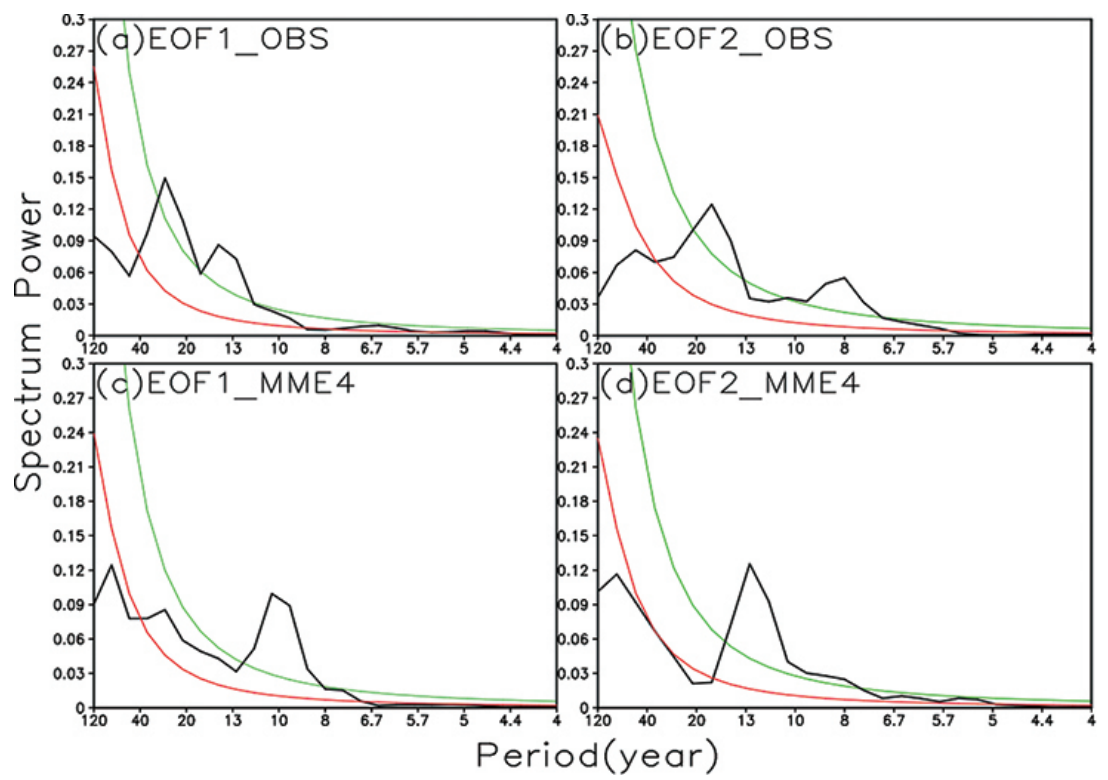

Fig. 10. Power spectrum of two dominant EOF modes of the North Pacific winter mean SSTA in MME4 and the observations. Black solid lines are power spectrum, with red solid lines (red) and $95 \%$ significant lines (green) shown. 
using CMIP5 model outputs in future scenarios. In this section, we use MME4 to examine the simulation performance of PDO and NPGO in two future emission scenarios (RCP4.5, RCP8.5) to investigate their possible changes in response to global warming.

The spatial patterns of the dominant modes in RCP4.5 and RCP8.5 scenarios are shown in Fig. 11. PDO is still the first mode in the North Pacific with even larger variance than that in the historical run. The spatial correlation coefficients with the observations are high. The second mode displays the NPGO pattern with a slight fluctuation in the amplitude strength. The south dipole of NPGO weakens in the RCP4.5 scenario and re-enhances in the RCP8.5 scenario. The strength of the north dipole is faint and modest in both RCP4.5 and RCP8.5 scenarios.

Earlier studies argued that global warming would lead to stronger ocean stratification (Saenko 2006), accelerate Rossby wave transport, and shorten the period of PDO (Fang et al. 2014). If this is the case, how would the temporal characteristics of PDO and NPGO perform based on CMIP5 model outputs in future scenarios? With the MME4 simulation results in future scenarios, we examine the power spectrum of PDO and NPGO (Fig. 12). In the RCP4.5 scenario, the PDO's peak is around 10 years with weakened power compared to the historical scenario. In the RCP8.5 scenario, the period shifts to 8 years and the spectrum power continues to weaken. For NPGO, the main period is around 8 years in the RCP4.5 scenario, shorter than that in the historical run. Moreover, in the RCP8.5 scenario, the NPGO's period is shortened to 6 years and the spectrum power weakens severely. The overall results suggest that under the global warming scenario, the two dominant low-frequency modes in the North Pacific simulated by the MME4 weaken and shift to a higher frequency, confirming the conclusions of previous studies to some extent.

\section{Conclusions and discussions}

In this study, we evaluate two dominant low-frequency modes in the North Pacific simulated by 24 models of CMIP5 model outputs. Further, we examine the air-sea coupling relationship simulation performance and select four models with better simulation capability both of the SSTA variability and the airsea coupling relationship. The multimodel ensemble of these four models (MME4) captures the spatial and temporal characteristics of PDO and NPGO well and depicts some changes in the temporal characteristics in future scenarios. The main results can be summarized as follows:
1. Twenty-four CMIP5 models are generally capable of simulating the spatial patterns of PDO and NPGO with a strong inter-model spread. In addition, the performance of the air-sea coupling relationship of each mode is model dependent. Most of the models fail to simulate the air-sea coupling relationship of the second mode.

2. The multimodel ensemble mean of the four selected models (MME4) shows some progress in simulating the spatial and temporal characteristics of PDO and NPGO compared with most of the individual models and the MME, especially the period features. The period of PDO simulated by the MME4 is around 8-15 years, whereas the NPGO's predominant period is around 15 years.

3. In future scenarios, spatial patterns of PDO and NPGO are substantially consistent; only the amplitudes of the two NPGO dipoles fluctuate slightly. However, the temporal patterns of PDO and NPGO change substantially. Both modes are weakened and shifted to a higher frequency in the RCP4.5 and RCP8.5 scenarios, which may support the conclusion of stronger ocean stratification under global warming conditions noted in related research.

Characterizing low-frequency variability in the North Pacific in models and the corresponding variation under global warming conditions is critical for understanding climate dynamics at present. Nevertheless, there still exists a great model spread for lowfrequency variability in the North Pacific simulated by the CMIP5 models in this study as well as in many other studies, which may affect confidence in the climate variability simulation. The model spread should be reduced as much as possible in the next stage of the model intercomparison project.

Considering that there is no optimized method to control the model spread at present, this study provides a method of model selection on the basis of spatial and temporal characteristics and dynamic mechanism as a feasible optimization scheme to diminish the model system error. This study does not, however, offer a comprehensive view on the causes of the North Pacific decadal variability. We solely select atmospheric forcing as the main factor causing North Pacific decadal variability, which may be somewhat subjective. Hence, in future studies, we hope to improve the model selection method, such as by adding other important factors (e.g., the Kuroshio Extension Meridional Mode) driving the North Pacific decadal variability. 

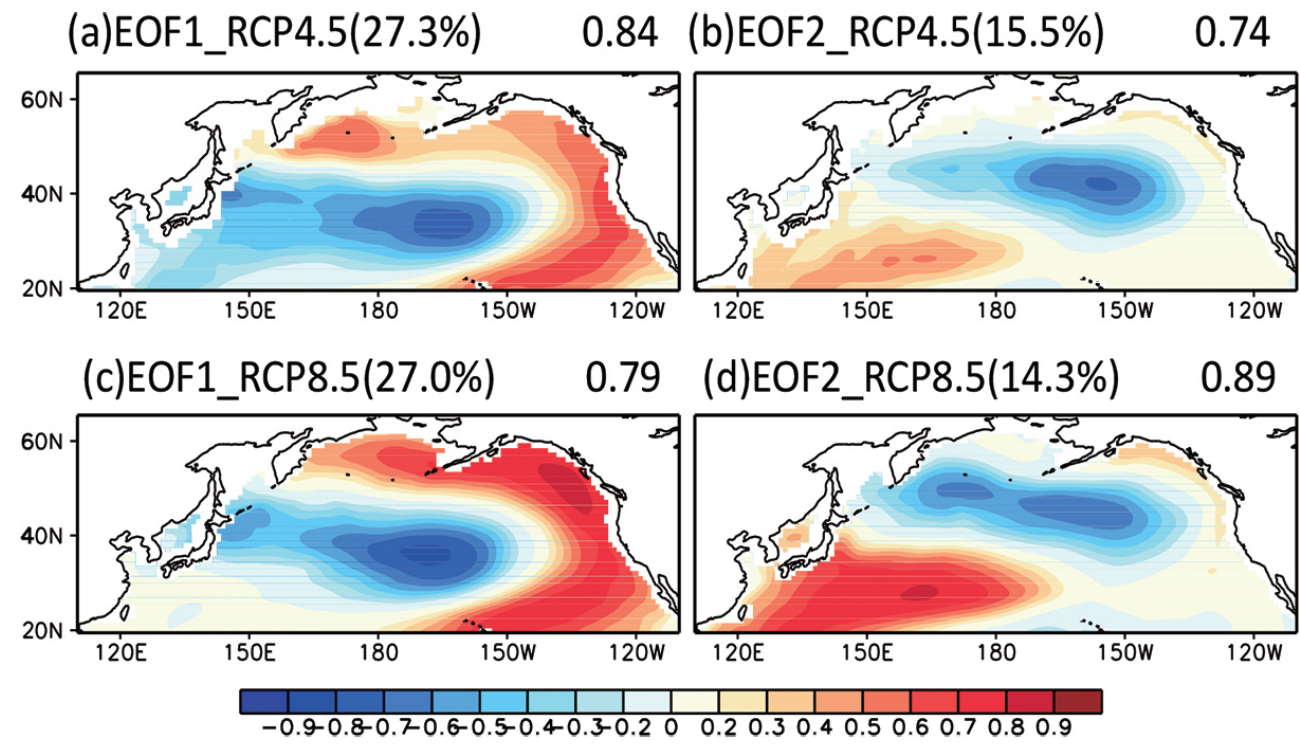

Fig. 11. Two dominant EOF modes of the North Pacific winter mean SSTA in RCP4.5 and RCP8.5 scenarios in MME4.

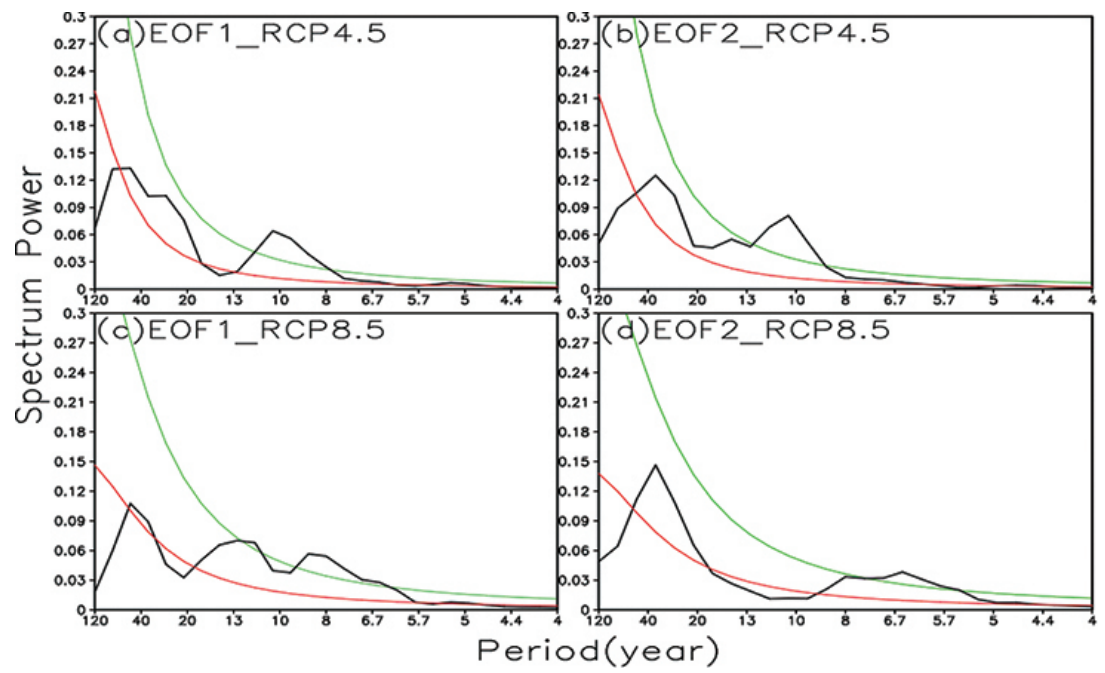

Fig. 12. Same as Fig. 8, but for results in RCP4.5 and RCP8.5 scenarios in MME4.

Related studies have indicated that under global warming conditions the ocean stratification strengthens, oceanic Rossby waves accelerate, the North Pacific transit time shortens, and PDO weakens and shifts to a higher frequency. In this study, the evaluation results using selected CMIP5 models show that PDO and NPGO tend to weaken and shift to higher frequencies in global warming emission scenarios. However, the dynamic mechanism of these changes is still unclear. In further studies, we hope to explore possible causes of the changes in temporal characteristics changes by using a better model selection method.

\section{Acknowledgments}

This work was supported by the National Natural Science Foundation of China (NSFC) (Grant Nos. 41276002 and 41130859), the National Basic Research Program of China (Grant No. 2013CB956201), and the NSFC-Shandong Joint Fund for Marine Science Research Centers (Grant No. U1406401). 


\section{References}

Chhak, K. C., E. Di Lorenzo, N. Schneider, and P. F. Cummins, 2009: Forcing of low-frequency ocean variability in the northeast Pacific. J. Climate, 22, 1255-1276.

Compo, G. P., J. S. Whitaker, P. D. Sardeshmukh, N. Matsui, R. J. Allan, X. Yin, B. E. Gleason, R. S. Vose, G. Rutledge, P. Bessemoulin, S. Brönnimann, M. Brunet, R. I. Crouthamel, A. N. Grant, P. Y. Groisman, P. D. Jones, M. C. Kruk, A. C. Kruger, G. J. Marshall, M. Maugeri, H. Y. Mok, Ø. Nordli, T. F. Ross, R. M. Trigo, X. L. Wang, S. D. Woodruff, and S. J. Worley, 2011: The twentieth century reanalysis project. Quart. J. Roy. Meteor. Soc., 137, 1-28.

Di Lorenzo, E., N. Schneider, K. M. Cobb, P. J. S. Franks, K. Chhak, A. J. Miller, J. C. McWilliams, S. J. Bograd, H. Arango, E. Curchitser, T. M. Powell, and P. Rivière, 2008: North Pacific Gyre Oscillation links ocean climate and ecosystem change. Geophys. Res. Lett., 35, L08607, doi:10.1029/2007GL032838.

Di Lorenzo, E., N. Schneider, K. M. Cobb, J. C. Furtado, and M. A. Alexander, 2010: ENSO and the North Pacific Gyre Oscillation: An integrated view of Pacific decadal dynamics. Proceeding of 22nd Conf. on Climate Variability and Change, Amer. Meteor. Soc., Atlanta, GA.

Fang, C., L. Wu, and X. Zhang, 2014: The impact of global warming on the Pacific Decadal Oscillation and the possible mechanism. Adv. Atmos. Sci., 31, 118-130.

Fleming, L. E., and K. J. Anchukaitis, 2016: North Pacific decadal variability in the CMIP5 last millennium simulations. Climate Dyn., 3783, doi:10.1007/s00382016-3041-7.

Furtado, J. C., E. Di Lorenzo, N. Schneider, and N. A. Bond, 2011: North Pacific decadal variability and climate change in the IPCC AR4 models. J. Climate, 24, 3049-3067.

Graham, N. E., 1994: Decadal-scale climate variability in the tropical and North Pacific during the 1970s and 1980s: Observations and model results. Climate Dyn., 10, 135-162.

IPCC, 2013: Climate Change 2013: The Physical Science Basis. Contribution of Working Group 1 to the Fifth Assessment Report of the Intergovernmental Panel on Climate Change. Stocker, T. F., D. Qin, G.-K. Plattner, M. M. B. Tignor, S. K. Allen, J. Boschung, A. Nauels, Y. Xia, V. Bex, and P. M. Midgley (eds.), Cambridge Univ. Press, Cambridge, U. K., and New York, USA, doi:10.1017/CBO9781107415324.004.

Jha, B., Z.-Z. Hu, and A. Kumar, 2014: SST and ENSO variability and change simulated in historical experiments of CMIP5 models. Climate Dyn., 42, 2113-2124.

Lapp, S., J.-M. St. Jacques, E. Barrow, and D. Sauchyn, 2011: GCM projections for the Pacific Decadal Oscillation under greenhouse forcing for the early $21 \mathrm{st}$ century. Int. J. Climatol., 31, 1423-1442.

Latif, M., and T. P. Barnett, 1994: Causes of decadal climate variability over the North Pacific and North America. Science, 266, 634-637.

Mantua, N. J., S. R. Hare, Y. Zhang, J. M. Wallace, and R. C. Francis, 1997: A Pacific interdecadal climate oscillation with impacts on salmon production. Bull. Amer. Meteor. Soc., 78, 1069-1079.

Newman, M., G. P. Compo, and M. A. Alexander, 2003: ENSO-forced variability of the Pacific decadal oscillation. J. Climate, 16, 3853-3857.

North, G. R., T. L. Bell, R. F. Cahalan, and F. J. Moeng, 1982: Sampling errors in the estimation of empirical orthogonal functions. Mon. Wea. Rev., 110, 699-706.

Overland, J. E., and M. Wang, 2007: Future climate of the north Pacific Ocean. Eos, 88, 178-182.

Overland, J. E., J. M. Adams, and N. A. Bond, 1999: Decadal variability of the Aleutian Low and its relation to high-latitude circulation. J. Climate, 12, 1542-1548.

Park, J.-H., S.-I. An, S.-W. Yeh, and N. Schneider, 2013: Quantitative assessment of the climate components driving the pacific decadal oscillation in climate models. Theor. Appl. Climatol., 112, 431-445.

Rogers, J. C., 1981: The North Pacific Oscillation. J. Climatol., 1, 39-57.

Saenko, O. A., 2006: Influence of global warming on baroclinic Rossby radius in the ocean: A model intercomparison. J. Climate, 19, 1354-1360.

Taylor, K. E., 2001: Summarizing multiple aspects of model performance in a single diagram. J. Geophys. Res., 106, 7183-7192.

Vimont, D. J., J. M. Wallace, and D. S. Battisti, 2003: The seasonal footprinting mechanism in the pacific: Implications for ENSO. J. Climate, 16, 2668-2675.

Wang, H., A. Kumar, W. Wang, and Y. Xue, 2012: Influence of ENSO on Pacific decadal variability: An analysis based on the NCEP climate forecast system. J. Climate, 25, 6136-6151.

Yi, D. L., L. Zhang, and L. Wu, 2015: On the mechanisms of decadal variability of the North Pacific Gyre Oscillation over the 20th century. J. Geophy. Res., 120, 6114-6129.

Yim, B. Y., M. Kwon, H. S. Min, and J. S. Kug, 2015: Pacific Decadal Oscillation and its relation to the extratropical atmospheric variation in CMIP5. Climate Dyn., 44, 1521-1540.

Zhang, L., and T. L. Delworth, 2015: Analysis of the characteristics and mechanisms of the Pacific Decadal Oscillation in a suite of coupled models from the Geophysical Fluid Dynamics Laboratory. J. Climate, 28, 7678-7699.

Zhang, L., and T. L. Delworth, 2016: Simulated response of the Pacific decadal oscillation to climate change. $J$. Climate, 24, 5999-6018.

Zhou, T., X. Chen, L. Dong, B. Wu, W. Man, L. Zhang, R. Lin, J. Yao, F. Song, and C. Zhao, 2014: Chinese contribution to CMIP5: An overview of five Chinese models' performances. J. Meteor. Res., 28, 481-509. 